\title{
High Resolution Sonography in Diagnosis of Metastatic Cervical Lymph Nodes in Oral Squamous Cell Carcinoma
}

\author{
SMA SADAT ${ }^{\mathrm{a}}$, SN RITA $^{\mathrm{b}}$, AU ZAMAN ${ }^{\mathrm{c}}$, A RAB $^{\mathrm{d}}$, MM HUSAIN $^{\mathrm{e}}, \mathrm{M} \mathrm{AHMED}^{\mathrm{f}}$
}

\begin{abstract}
:
Ultrasound is reported superior to clinical palpation for detecting lymph nodes and metastasis. The advantage of ultrasound over other imaging modalities is price, low patient burden, and possibilities for follow up. A cross sectional Study on 29 cases of oral squamous cell carcinoma was done in Department of Oral \& Maxillofacial Surgery, Dhaka Dental College \& Hospital, Dhaka from January 2006 to December 2007. The sensitivity, specificity, positive predictive value, negative predictive value \& Accuracy of Ultrasonographic technique for determining metastatic
\end{abstract}

\section{Introduction:}

Oral Cancer is used to describe any malignancy arises from oral soft and hard tissues. Approximately 90\% of oral cancers are Squamous cell carcinoma (SCC). Globally, oral cancer is one of the ten most common cancers and it is the second major cause of death after heart disease ${ }^{1}$. It is a major health problem in the Indian sub continent ${ }^{2}$. According to the WHO, about $90 \%$ of the oral Squamous Cell Carcinoma in South East Asia is attributable to tobacco use in its different forms and in Bangladesh it is the main aetiological factor ${ }^{3}$.

a. Dr. S. M. Anwar Sadat, BDS, MCPS, FCPS, MS (OMS), Lecturer, Dhaka Dental College \& Hospital

b. Dr. Sufia Nasrin Rita, BDS, FCPS, Assistant Professor, Sapporo Dental College

c. Prof. Dr. Asad-Uz-Zaman, BDS, DDS, PhD, Head, Dept. of Oral Pathology, Sapporo Dental College

d. Dr. Md. Abdur Rob, BDS, FCPS, Lt. Col, CMH, Dhaka.

e. Dr. Md. Musharraf Husain, Consultant Sonologist \& Radiologist, Ibn Sina Diagnostic \& Imaging, Dhaka.

f. Prof. Dr. Mohiuddin Ahmed, BDS, FCPS, PhD, Head, Dept. of Oral \& Maxillofacial Surgery, Dhaka Dental College \& Hospital.

Address of Correspondence: Dr. S. M. Anwar Sadat, BDS, MCPS, FCPS, MS (OMS), Lecturer, Dept of Oral \& Maxillofacial Surgery Dhaka Dental College \& Hospital, e-mail: an_sadat@yahoo.com.

Received: 7 July, 2009

Accepted: 18 November, 2009 cervical lymph node were 93.33\%, 50\%, 66.7\%, 87.5\% and $72.4 \%$ respectively. Considering the finding of the study, Sonographic evaluation can improve the diagnosis of metastatic cervical lymph node in patients with oral squamous cell carcinoma. It is cost effective, non-invasive, less burden to patient, does not create problem of overlapping with mandible and can be done repeatedly to follow up. Therefore, high resolution sonography may be an adjunct tool in diagnosing metastatic nodes in patients with oral squamous cell carcinoma.

(J Bangladesh Coll Phys Surg 2010; 28: 92-99)

The single most important factor in determining prognosis of Oral Cancer is whether regional nodal metastasis is present. Survival rates decrease by $50 \%$ when nodal metastases are present; a contra lateral node reduces survival by an additional $50 \%$. Consequently bilateral nodal involvement reduces survival actually by $75 \%$ and extra nodal involvement reduces this by another $50 \%{ }^{4}$. Furthermore, the presence of cervical adenopathy has been correlated with an increase in the rate of distant metastasis 5 .

Pre-operative assessment of the cervical lymph node status helps in planning suitable surgical management of the neck, wherein the justification to operate the neck is being questioned more often than not, owing to the fact that only about $30 \%$ of clinically negative necks are histopathologically positive once operated ${ }^{6}$.

Evaluating neck metastasis based on physical examination findings has been the classic method for patients of new tumors in the head and neck. During the clinical evaluation, careful palpation of the neck, with specific attention to number, position, size, shape, consistency, tenderness and mobility of each node, is noted. Attention is particularly directed to nodes that appear fixed to underlying neurovascular structures, visceral organs, or nodes that demonstrate skin infiltration. The description of each becomes an 
important part of the medical record, which can be used to assess the response to treatment of progression of the disease.

Unfortunately clinical palpation of the neck demonstrates a large variation of findings among various examinations. Although both inexpensive to perform and repeat, palpation findings are generally accepted as inaccurate. Here sensitivity and specificity are in the range of $60-70 \%$, depending on the tumor studied. Because of the knowledge of sensitivity and specificity of palpation, a neck side without palpable metastasis is still at risk of harboring occult metastasis, with the risk determined by the characteristics of the primary tumor. The incidence of false negative (occult) nodes based on physical examination findings varies in the literature from $16-60 \%{ }^{6}$. Before the introduction of diagnostic imaging, clinical palpation was shown to be inadequate for detecting cervical lymph node metastasis. Soko et al reported that only $28 \%$ of occult cervical metastases were found by clinical palpation. Fischbein et al. have found clinical examination to have only $70 \%$ accuracy at best ${ }^{7}$.

Several imaging modalities are used in evaluating the status of lymph nodes in oral cavity cancer, ranging from Ultrasound imaging, Contrast Enhanced Computed Tomography (CECT), Magnetic Resonance Imaging (MRI) to 2-Fluoro-2-deoxy-glucose (FDG) Positron Emission Tomography (FDG-PET) and Lymphoscintigraphy. Ultrasound is reported superior to clinical palpation for detecting lymph nodes and metastasis. The advantage of ultrasound over other imaging modalities is price, low patient burden, and possibilities for follow up ${ }^{8}$.

Sonograph of Metastatic lymph node disease characteristically find enlargement with a spherical shape. Affected nodes are hypo echoic, with a loss of hilar definition. In cases of extra-nodal spread with infiltrative growth, the nodal margins are poorly defined. Common findings of metastasis from Squamous cell carcinoma are extra-nodal spread and central necrosis together with liquid areas in the lymph nodes. Lymph node metastasis from malignant melanoma and the papillary thyroid carcinoma have a non-echoic appearance that mimic a cystic lesion. Sonography may also be helpful for assessing invasion of the carotid artery and jugular vein. Torabi et al have reported an accuracy of 89 to $92 \%$ for ultrasound imaging in detecting cervical nodal metastasis ${ }^{9}$. However several authors have shown its sensitivity ranging from $69-81 \%$ and positive predictive value of $70-83 \%$. Ariji Y et al concluded that ultrasonic criteria of no hilar flow, peripheral parenchymal nodal flow, and transverse to longitudinal ratio of more than 0.65 together constitute a powerful tool for depicting Metastatic lymph nodes in patients with cancer ${ }^{10}$.

Though many studies were done in other countries with successful outcome to assess the metastatic cervical lymph nodes in oral cancer patients, in our country no study has so far been done on this regard. The present study hopefully will achieve the goal.

\section{Patients \& Methods:}

The cross sectional Study on 29 cases of oral squamous cell carcinoma was done in Department of Oral \& Maxillofacial Surgery, Dhaka Dental College \& Hospital, Dhaka from January 2006 to December 2007

Patients having histologically confirmed Oral Squamous Cell Carcinoma attending at Dhaka Dental College \& Hospital were selected for the study. By convenient sampling 29 cases of such Oral Squamous Cell Carcinoma patients were selected \& after taking informed written consent they were evaluated clinically and by High Resolution Sonography (HRSG) for neck metastasis. Standard treatment was provided to all patients being included in the study.

Inclusion Criteria:

All patients diagnosed histologically as Squamous Cell Carcinoma in Oral Cavity

(1) Patients of Oral Squamous Cell Carcinoma with or without clinical evidence of Metastatic cervical lymph nodes

Exclusion Criteria:

(1) Patient of Oral Squamous Cell Carcinoma declared as inoperable for the primary tumor

(2) Patient of Oral Squamous Cell Carcinoma declared as inoperable for advanced neck metastasis

(3) Patient of Oral Squamous Cell Carcinoma declared as inoperable for systemic illness

Data Collection Method:

Data were collected through written questionnaire, clinical examination and by investigation (High 
Resolution Sonography Machine). Evaluation of cervical lymph node metastasis was done by clinical palpation with a single investigator and Ultrasonogram by using the HRSG machine (High Frequency Probe at $10 \mathrm{MHz}$ with range of 5-12) in a single centre (Ibn Sina Imaging Centre, Dhaka) operated by an experienced single Sonologist. The result of the modality was compared with post operative histopathological examination.

Data Processing and Analysis:

Data were processed and analyzed using computer software SPSS (Statistical Package for Social Science) version 12 . The test statistics used to analyze the data were descriptive statistics, Pearson Chi-square test. The data presented on categorical scale were expressed as frequency and corresponding percentage, while the quantitative data were presented as mean and standard deviation (SD) from the mean. Association between two variables was justified using Pearson Chi-square test. For all analyses, level of significance was set at 0.05 and p-value $<0.05$ was considered significant.

\section{Results:}

Figure 1 shows that majority of the study subjects belonged to the age group of 40-49 years (about 34.5\%) followed by the age group 60-69 years (about 24.1\%). The age of the study subjects who fulfilled the inclusion criteria ranged from 35 - 85 years (Mean age +/$\mathrm{SD}=53.48+/-12.45$ years)

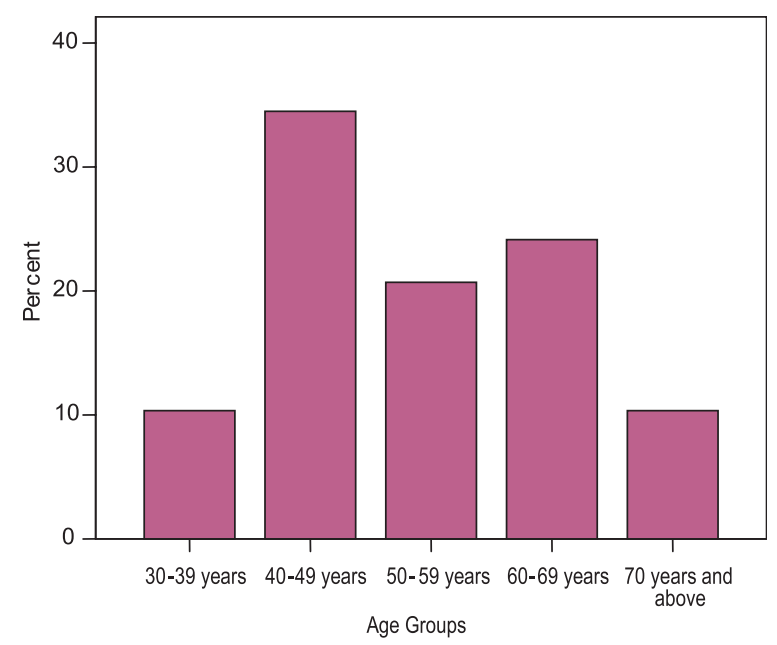

Fig 1: Age group distribution of study patients $(n=29)$
Figure 2 shows that $58.6 \%$ of the study subjects were male, while remaining $41.4 \%$ of them were female.

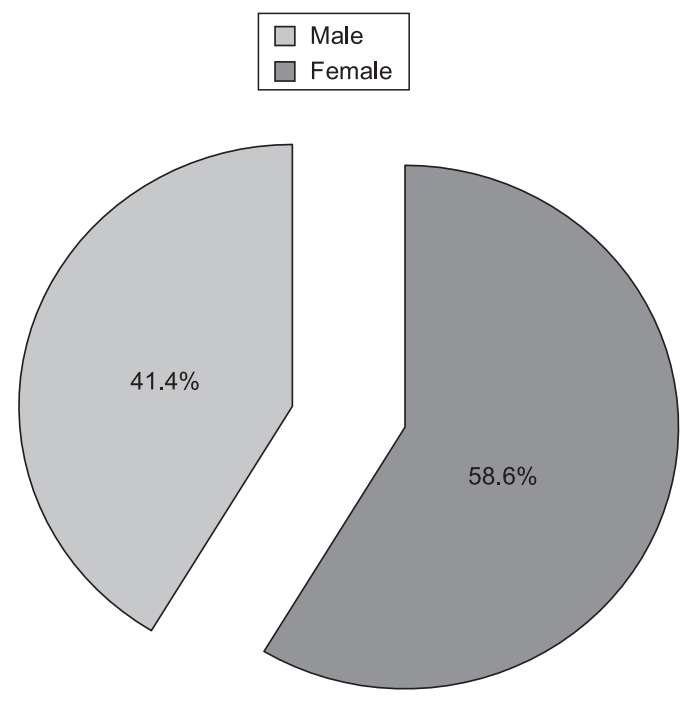

Fig 2: Sex distribution of study patients $(n=29)$

Figure 3 shows that about half (51.7\%) of the lesions located in the alveolar ridge. Beside the alveolar ridge the other common sites were Buccal mucosa (27.6\%) followed by retro molar area (13.8\%). Tongue and floor of the mouth were affected with the same frequency (3.4\%).

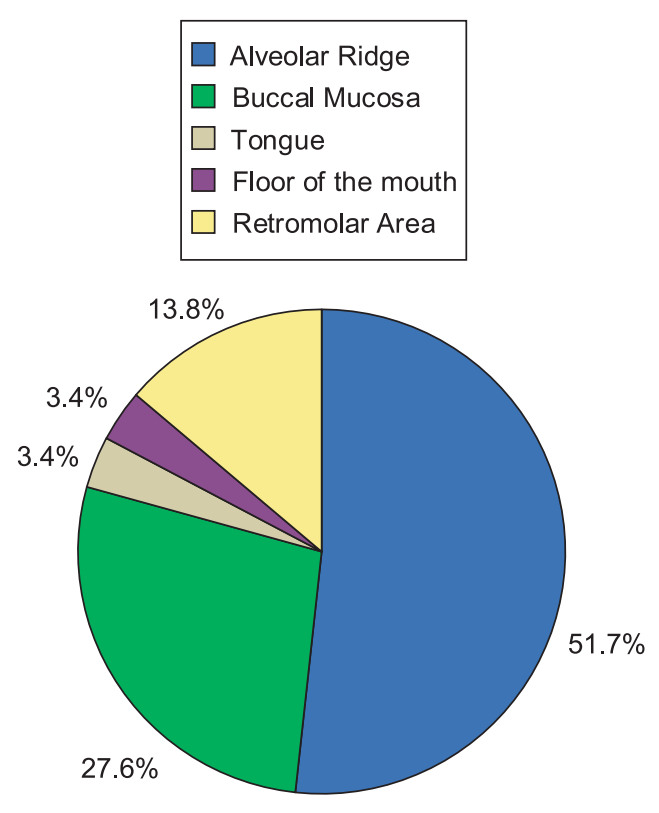

Fig 3: Site distribution of study patients 
Figure 4 shows that about half of the study subjects (51.7\%) were habituated to betel quid chewing followed by $37.9 \%$ and $10.3 \%$ habituated to smoking and betel quid-smoking respectively.

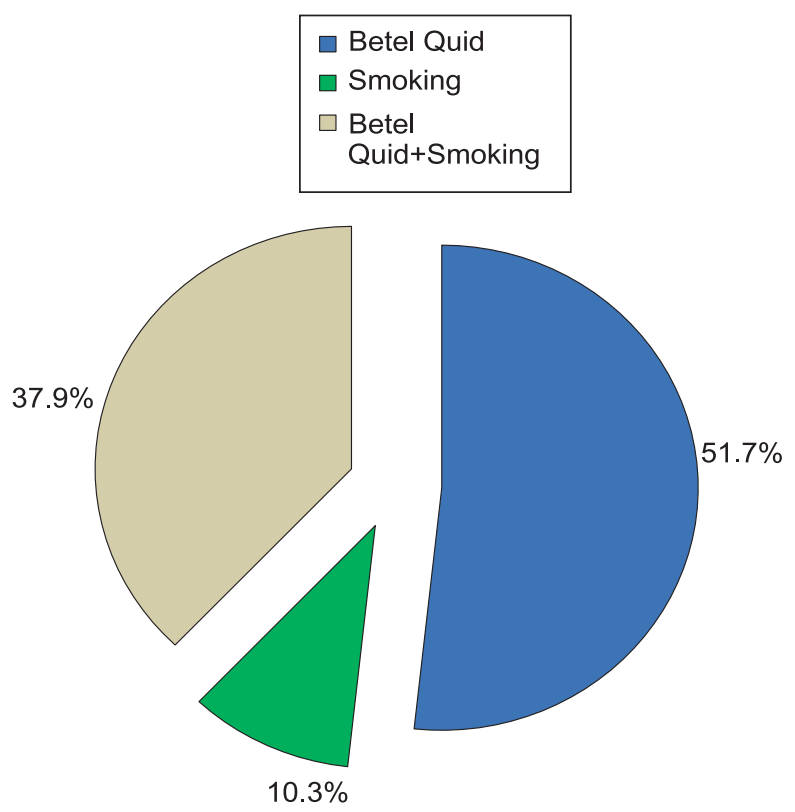

Fig 4: Distribution of patients by their habits $(n=29)$

Figure 5 shows that Grade I lesions was most prevalent in the study subjects (75.9\%). $20.7 \%$ and $3.4 \%$ of the lesions were Grade II and Grade III respectively in the conventional grading system.

Histologic Type of Primary Lesion (Conventional Grading)



Fig 5:
Figure 6 shows that most of the cases were Stage IV (55.2\%) followed by 31\% Stage III, 10.3\% Stage II and $3.4 \%$ Stage I lesion in TNM Staging system.

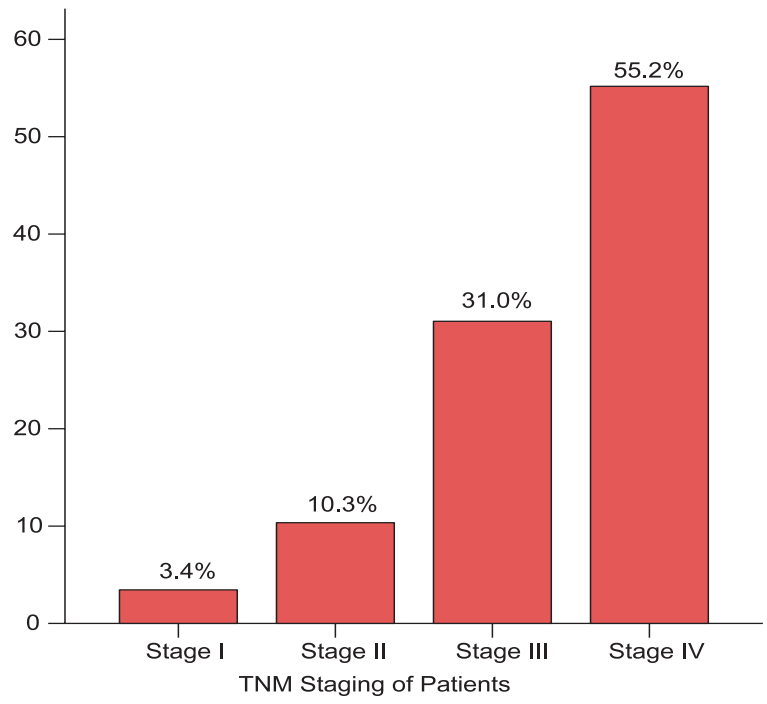

Fig 6: Distribution of patients by TNM Staging $(n=29)$

Table-I

Distribution of study subjects by clinical type \& grading of primary lesion $(n=29)$

Clinical Type Grading Total of Lesion

Grade I Grade II Grade III

\begin{tabular}{lcccc}
\hline Ulcerative & $16(76.2 \%)$ & $4(19.0 \%)$ & $1(4.8 \%)$ & $21(100 \%)$ \\
Exophytic & $4(66.7 \%)$ & $2(33.3 \%)$ & $0(0 \%)$ & $6(100 \%)$ \\
Verrucous & $2(100 \%)$ & $0(0 \%)$ & $0(0 \%)$ & $2(100 \%)$ \\
\hline Total & $22(75.9 \%)$ & $6(20.7 \%)$ & $1(3.4 \%)$ & $29(100 \%)$ \\
\hline
\end{tabular}

Table 1 shows that most of the ulcerative lesions were Grade-I (76.2\%) which is similar to exophytic and verrucous lesions.

\section{Table-II}

\begin{tabular}{|c|c|c|c|c|}
\hline \multicolumn{5}{|c|}{$\begin{array}{c}\text { Association between clinical staging and } \\
\text { pathological staging of lymph node }\end{array}$} \\
\hline \multirow{2}{*}{$\begin{array}{l}\text { Clinical } \\
\text { Staging of } \\
\text { Lymph }\end{array}$} & \multicolumn{3}{|c|}{$\begin{array}{l}\text { NodePathological Staging } \\
\text { of Lymph Node }\end{array}$} & \multirow[t]{2}{*}{ Total } \\
\hline & $\mathrm{N}_{0}$ & $\mathrm{~N}_{1}$ & $\mathrm{~N}_{2}$ & \\
\hline$\overline{\mathrm{N}_{0}}$ & $6(100 \%)$ & $0(0 \%)$ & $0(0 \%)$ & $6(100 \%)$ \\
\hline $\mathrm{N}_{1}$ & $6(31.6 \%)$ & $12(63.2 \%)$ & $1(6.3 \%)$ & $19(100 \%)$ \\
\hline $\mathrm{N}_{2}$ & $0(0 \%)$ & $1(25 \%)$ & $3(75 \%)$ & $4(100 \%)$ \\
\hline Total & $12(41.4 \%)$ & $13(44.8 \%)$ & $4(13.8 \%)$ & $29(100 \%)$ \\
\hline
\end{tabular}


Table 2 shows the cross tabulation between clinical staging of lymph nodes and pathological staging of lymph nodes. Clinically suspected all $\mathrm{N}_{0}$ neck was confirmed by histological examination. 63.2\% of clinically suspected $\mathrm{N} 1$ case was confirmed by histological examination where $31.6 \%$ become $\mathrm{N}_{0}$ and $6.3 \%$ become $\mathrm{N}_{2}$.

\section{Table-III}

\section{Relationship between Palpation Finding of Lymph Node \& Histological Finding of Lymph Node}

\begin{tabular}{lccc} 
Palpation & \multicolumn{2}{l}{ Histological Finding of LN } & Total \\
\cline { 2 - 3 } $\begin{array}{l}\text { Finding of } \\
\text { Lymph Node }\end{array}$ & & & \\
\cline { 2 - 3 } & Positive & Negative & \\
\hline Positive & $14(73.7 \%)$ & $5(26.3 \%)$ & $19(100 \%)$ \\
Negative & $1(10 \%)$ & $9(90 \%)$ & $10(100 \%)$ \\
\hline Total & $15(51.7 \%)$ & $14(48.3 \%)$ & $29(100 \%)$ \\
\hline
\end{tabular}

It was found that sensitivity, specificity, positive predictive value, negative predictive value $\&$ accuracy of palpation method for determining metastatic cervical lymph node were 93.33\%, 64.29\%, 73.68\%, 90\% \& $79.3 \%$ respectively.

\section{Table-IV}

Relationship between Ultrasonographic Finding of Lymph Node \& Histological Finding of Lymph Node

\begin{tabular}{lcrr}
\multirow{2}{*}{\begin{tabular}{l} 
Ultrasonographic $\begin{array}{l}\text { Finding of } \\
\text { Lymph Node }\end{array}$ \\
\cline { 2 - 3 }
\end{tabular}} & \multicolumn{2}{c}{$\begin{array}{c}\text { Histological } \\
\text { Finding of LN }\end{array}$} & \multicolumn{1}{c}{ Total } \\
\cline { 2 - 3 } & Positive & Negative & Positive \\
\hline Negative & $14(66.7 \%)$ & $7(33.3 \%)$ & $21(100 \%)$ \\
\hline Total & $1(12.5 \%)$ & $7(87.5 \%)$ & $8(100 \%)$ \\
\hline
\end{tabular}

The sensitivity, specificity, positive predictive value, negative predictive value \& Accuracy of Ultrasonographic technique for determining metastatic cervical lymph node were 93.33\%, 50\%, 66.7\%, 87.5\% and $72.4 \%$ respectively

\section{Discussion:}

The study was performed in Department of Oral \& Maxillofacial Surgery, Dhaka Dental College \& Hospital from January 2006 to December 2007, where significant number of oral squamous cell carcinoma patients attended regularly. Among them 29 study subjects were selected conveniently who fulfilled the inclusion criteria. The endeavor was initiated with the aim of evaluating the contribution of high resolution sonography to evaluate the metastatic cervical lymph node in oral Squamous cell carcinoma.

According to the study, $58.6 \%$ of the total study subjects were male which finding corresponds to other studies on Bangladeshi patients (53\% by $\operatorname{Sitan}^{23}, 56.5 \%$ by Adhikari ${ }^{24}$ ). The age ranged from 35 to 85 years where majority of the study subjects (34.5\%) belonged to the age group of 40-49 years. This data showed similarity with Shaheed ${ }^{3}$ et al and corresponds with the information of Sitan ${ }^{23} 2006$ (50-59 years) and Adhikari $^{24} 2006$ (60-69 years) and Langdon ${ }^{25}$ et al 1992 (70-79 years).

On clinical examination we found that about half of the lesions $(51.7 \%)$ were located in the alveolar ridge. Beside the alveolar ridge the other common sites were Buccal mucosa (27.6\%) followed by retro molar area (13.8\%). Tongue and floor of the mouth were affected with the same frequency (3.4\%). This distribution is almost similar to $\operatorname{Sitan}^{23} 2006$ but showed disparity with Richard ${ }^{26}$ et al and $\mathrm{Hsie}^{27}$ et al.

Personal habits of the patients were taken into consideration as a risk factor for oral Squamous cell carcinoma. Habit of betel nut chewing was present among $51.7 \%$ patients which is almost similar to other investigators $3,23,24,28,29$. The second most common habit was smoking (37.9\%) which was followed by both betel quid and smoking (10.3\%).

Histopathologically $75.9 \%$ of our study specimen were well differentiated, $20.7 \%$ moderately differentiated and $3.4 \%$ poorly differentiated. This finding is almost similar to Shaheed $^{3}$ et al which is $72 \%, 18 \%$ and $6 \%$ respectively.

Regional metastasis is one of the most important factors in the prognosis and treatment of patients with head and neck squamous cell cancer ${ }^{4}, 5$. In addition, because lymphatic metastasis is a frequent event that impacts prognosis, a decision to treat the lymph nodes in the neck has to be made in almost all patients, even if metastases are not apparent clinically. It is therefore important to assess as reliably as possible whether a patient has regional lymph node metastases.The 
presence of cervical lymph node metastasis in oral squamous cell carcinoma often also changes the extent of surgical treatment or radiotherapy and chemotherapy..

It is well known that palpation is an inaccurate technique to stage cancer in the neck ${ }^{30}$. In a recent decisionanalysis study, a risk of occult neck metastases (in a palpatory-negative neck) above $20 \%$ was found to be indicative for elective neck treatment, either radiation therapy or surgery. This risk of occult metastasis, which can occur in both sides of the neck, is determined by characteristics of the primary tumor such as size, site, and several biological criteria ${ }^{11}$. Because of the increased risk of nodal metastases, even in clinically negative necks, most patients with tumors staged as T2 or larger undergo some form of elective neck treatment. The disadvantage of this policy is that the majorities of patients do not harbor metastases and, therefore, will be subjected to the morbidity of unnecessary treatment. By detecting some otherwise clinically occult adenopathy, modern imaging techniques may have increased sensitivity for detecting positive nodes, and consequently, may decrease the risk of occult metastasis to below $20 \%$. If this can be accomplished, the clinician may refrain from a neck dissection or radiation, and adapt a wait-and-see policy with careful follow-up to detect a neck metastasis as early as possible ${ }^{12}$.

The drawback of palpation method for evaluating neck lymph node is that it is a subjective method and is totally operator and experience dependent. It can be competitive with other investigation modalities if the skill can be improved by repeated examinations of neck. In our study subjects we examined the necks repeatedly for quality evaluation of cervical lymph nodes.

In the study, sensitivity, specificity, positive predictive value, negative predictive value $\&$ accuracy of palpation method for determining metastatic cervical lymph node were $93.33 \%$, 64.29\%, 73.68\%, 90\% \& 79.3\% respectively. This result is comparable to Chowdhury 31 et al where the results are $75.6 \%, 60 \%, 88.6 \%, 37.5 \%$ and $72.5 \%$ and $\mathrm{Haberal}^{32}$ et al where the results are $64 \%, 85 \%, 78 \%, 74 \%$ and $75 \%$. The comparison proves that positive predictive value and accuracy rates are almost same in all studies though there are some dissimilarity exists in sensitivity, specificity and negative predictive value. It is to be mentioned here that in this study palpation method showed high sensitivity
(93.33\%) and specificity (64.29\%) which have limited clinical value as probably many metastatic lymph nodes were palpable. The sensitivity would have been lower if the study was limited to $\mathrm{N}_{0}$ neck population.

Imaging techniques like CT, MR, and sonography are more accurate than palpation. Most clinicians have maintained, however, that the accuracy of these techniques is not high enough to justify a change of policy. Indeed, in $25 \%$ of pathologically verified tumorpositive neck dissections, only micro metastases smaller than $3 \mathrm{~mm}$, which are undetectable by most techniques, are present ${ }^{13}$. Lymph nodes $2-3 \mathrm{~mm}$ in size can be seen as nodules on CT and MR images, and may even be better seen with high-resolution scanners. Nonetheless, differentiation between benign and malignantmetastatic disease still remains a problem. Recently, other techniques such as radioimmunoscintigraphy ${ }^{14}$ and positron emission tomography ${ }^{15}$ have been explored, but these expensive techniques still have to prove their value in clinical practice.

Sonographic criteria, such as nodal size and configuration of the lesion, and Doppler Sonographic criteria have been studied extensively for their value in differentiating between benign and malignant lymphatic disease in the neck. The minimal axial diameter appears to be the most accurate size criterion, compared to the maximal axial diameter and the longitudinal diameter 16, 17. Regarding the aspect of lymph nodes on sonograms, the echogenic hilus appears to be a reliable parameter ${ }^{17}$. The configuration (shape) of the node might be important, but some authors doubt its value ${ }^{18}$. Following the above criteria our study subjects were evaluated with a high resolution sonography machine with use of color \& power Doppler by a more than fifteen years experienced single investigator. After clinical and Sonographic evaluation the subjects were treated by neck dissection. All the detected lymph nodes were evaluated by thorough histopathological examinations by expert histopathologist.

In this study the sensitivity, specificity, positive predictive value, negative predictive value $\&$ accuracy of the Sonographic technique for determining metastatic cervical lymph nodes were 93.33\%, 50\%, 66.7\%, 87.5\% and $72.4 \%$ respectively. The respective values are comparable to other studies e.g. $72 \%$, $96 \%$, $94 \%, 80 \%$ and $85 \%$ by Haberal ${ }^{32}$ et al, $78 \%$ accuracy by Mikami ${ }^{33}$ 
et al, $94 \%$ accuracy by Steinkamp ${ }^{34}$ et al, and $92 \%$ sensitivity by Naito ${ }^{35}$ et al. The analysis proves that the accuracy of Sonographic technique is satisfactory (72.4\%) and almost similar to other studies abroad. The important drawback of this technique is that it is operator and skill dependent as like as other investigations.

Sonography-guided fine-needle aspiration cytology (FNAC) has been shown to be very accurate in the evaluation of regional metastatic disease. It combines the high sensitivity of sonography with the excellent specificity of FNAC. The reported sensitivity of sonography-guided FNAC in the N0 neck ranges from $48 \%$ to $73 \%{ }^{16,19,20}$, whereas the reported specificity is $100 \%{ }^{21}$. In the United States, this technique has received fewer acceptances because it is labor-intensive and operator-dependent. False-negative results may be the result of sampling the wrong node or the wrong part of the correct node. Furthermore, the cytopathologist may overlook small nests or single tumor cells.

\section{Conclusion:}

Considering to the finding of the study, Doppler Sonographic evaluation can improve the diagnosis of metastatic cervical lymph node in patients with oral squamous cell carcinoma. It is cost effective, noninvasive, less burden to patient, does not create problem of overlapping with mandible and can be done repeatedly to follow up. Although it has some limitations of operator and skill dependency, it predicts the presence of metastatic nodes with sensitivity equivalent and specificity near to that obtained with palpation method. Furthermore for the detection of nodes in the submental and submandibular regions where other modalities have occasionally been impaired by artifacts from bones and dental amalgam, the doppler Sonographic evaluation facilitates the early detection of metastatic nodes. Therefore, high resolution doppler sonography may be an adjunct tool in diagnosing metastatic nodes in patients with oral squamous cell carcinoma.

\section{References:}

2. Bruce R. Donoff Manual of oral \& Maxillofacial Surgery. $3^{\text {rd }}$ edition. Mosby 1997; 325.

3. ICMR, National Cancer Registry of Indian Council for Medical Research, Annual report 1984, 1987. New Delhi ICMR.

4. Shaheed SMI, Molla MR. Oral Cancer in Bangladesh: Its Aetiology and Histological Grading. J. of Oral Health 1996; 2:8-11.
5. Shah JP, Candela FC, Poddar AK: The patterns of cervical lymph node metastases from squamous carcinoma of the oral cavity. Cancer1990; 66: 109-113

6. Leemans CR, Tiwari R, Nauta JJP, Isaac van der Waal, Snow G. B: Regional lymph node involvement and its significance in the development of distant metastasis in head and neck carcinoma. Cancer 1993; 71: 452-456

7. Johnson JT. A Surgeon looks at cervical lymph nodes. Radiology 1990; 175:607-610.

8. Fischbein NJ, Noworolski SM, Henry RG, et al. Assessment of Metastatic cervical adenopathy using dynamic contrastenhanced MR imaging. Am J Neuroradiol 2003; 24:301-311

9. Ahuja A, Ying M, Yang WT, Evans R, et al. The use of Sonography in differentiating cervical lymphomatous lymph nodes from cervical Metastatic lymph nodes. Clinical Radiology 1996; 51: 186-190.

10. Torabi M, Aquino SL, Harisinghani MG: Current concepts in lymph node imaging. Journal of nuclear medicine 2004; 45: 1509-1518.

11. Ariji Y et al.: Power Doppler Sonography of cervical lymph nodes in patients with head and neck cancer. AJNR Am J Neuroradiol 1998; 19: 303-307.

12. Okamoto M, Ozeki S, Watanabe T, Lida Y, Tashiro H. Cervical lymph node metastasis in carcinoma of the tongue: correlation between clinical and histopathological findings and metastasis. J Craniomaxillofac Surg 1988; 16:31-34.

13. Weiss MH, Harrison LB, Isaacs RS. Use of decision analysis in planning and management strategy for the stage N0 neck. Arch Otolaryngol Head Neck Surg 1994;120:699-702

14. Van den Brekel MWM, Stel HV, Castelijns JA, et al. Cervical lymph node metastasis: assessment of radiologic criteria. Radiology 1990; 177:379-384.

15. van Dongen GA, Leverstein H, Roos JC, Quak JJ, van den Brekel MW, van Lingen A, et al. Radio-immunoscintigraphy of head and neck cancer using 99mTc-labeled monoclonal antibody E 48 F(ab')2. Cancer Res 1992; 52:2569-2574.

16. Braams JW, Pruim J, Nikkels PG, Roodenburg JL, Vaalburg W, Vermey A. Nodal spread of squamous cell carcinoma of the oral cavity detected with PET-tyrosine, MRI and CT. J Nucl Med 1996;37:897-901.

17. Van den Brekel MWM, Castelijns JA, Stel HV, et al. Occult metastatic neck disease: detection with US and US-guided fine needle aspiration cytology. Radiology 1991; 178:457461.

18. Chikui T, Yonetsu K, Nakamura T. Multivariate analysis of sonographic findings on metastatic cervical lymph nodes: contribution of blood flow features revealed by power Doppler sonography in predicting metastasis. AJNR Am J Neuroradiol 2000; 21:561-567.

19. Vassallo P, Wernecke K, Roos N, Peters PE. Differentiation of benign from malignant superficial lymphadenopathy: the role of high-resolution US. Radiology 1992; 183:215-220. 
20. Takes RP, Knegt PPM, Manni JJ, et al. Regional metastasis in head and neck squamous cell cancer: the value of ultrasound with USgFNAB revised. Radiology 1996;198:819-823

21. Righi PD, Kopecky KK, Caldemeyer KS, Ball VA, Weisberger EC, Radpour S. Comparison of ultrasound fine needle aspiration an computed tomography in patients undergoing elective neck dissection. Head Neck 1997; 19:604-610.

22. van den Brekel MWM, Reitsma LC, Quak JJ, et al. Sonographically guided aspiration cytology of neck nodes for selection of treatment and follow-up in patients with N0 head and neck cancer. AJNR Am J Neuroradiol 1999; 20:17271731.

23. Yonetsu K, Sumi M, Izumi M, Ohki M, Eida S, Nakamura T. Contribution of Doppler Sonography Blood Flow Information to the Diagnosis of Metastatic Cervical Nodes in Patients with Head and Neck Cancer: Assessment in Relation to Anatomic Levels of the Neck. American Journal of Neuroradiology 2001; 22:3-4.

24. Sitan KN. Expression of $\mathrm{P}^{53}$ protein in oral squamous cell carcinoma. Thesis submitted to Dhaka University 2006.

25. Adhikari RB. Study on histological pattern of mandibular bone invasion by oral squamous cell carcinoma. Thesis submitted to BSMMU 2006.

26. Langdon ZE, Parridge M. Expression of tumor suppressor gene $\mathrm{P}^{53}$ in oral cancer. J Oral Maxillofac Surg 1992;30:214220.

27. Richard PMD, Lawrence RMD, Willium JHMD. Cancer management: A multidisciplinary approach: Medical, Surgical and Radiation Oncology. $8^{\text {th }}$ edition. Oncology News International Cancer Network.com 2004;44.
28. Hsie LL, Wang PF, Chen IH. Characteristics of mutation in oral squamous cell carcinoma associated with betel quid chewing and cigarette smoking in Taiwanese. Carcinogenesis 2001;22:1497-1503.

29. Carter RL. Patterns and mechanism of localized bone invasion by tumors: studies with squamous carcinomas of head and neck. CRC Crit. Rev. Clin. Lab. Sci 1985;22:275-315

30. Totsuka Y. Results of surgical treatment for squamous cell carcinomas of lower alveolus: segmental vs. marginal resection. Head and Neck 1991;13:114-120.

31. Jonas A. Detection of lymph node metastasis in neck radiologic criteria. Am J of Neuroradio 2001;22:3-4.

32. Chowdhury RU. Detection of metastatic cervical lymph nodes: physical examination and contrast computed tomography vs nodal biopsy after neck dissection. Thesis submitted to Dhaka University 2005.

33. Haberal, I et al. Which is important in evaluation of metastatic lymph nodes in head and neck cancer: palpation, USG or Computed Tomography? Otolaryngol Head Neck Surg 2004;130:197-201.

34. Steinkamp HJ, et al. Reactive enlargement of cervical lymph nodes and cervical lymph node metastasis: sonography and computed tomography. Aktuelle Radiol 1992;2:188-95.

35. Mikami Y, et al. Ultra Sonographic evaluation of metastatic cervical lymph nodes in head and neck cancer. Nippon Jibiinkoka Gakkai Kaiho 2000;103:812-20.

36. Naito K. Analysis of cervical metastatic lymphadenopathy by Ultrasonography. Hoshasen Gakkai Zasshi 1990;50:91827. 